\title{
Research Paper: Spatial Analysis of Changes in Public Transport Passengers as a result of the Corona Pandemic in the Mashhad Suburban Area
}

\author{
Mostafa Amirfakhrian ${ }^{1 *}$, Hadye Hasanneya ${ }^{2}$ \\ 1. Assistant Professor, Ferdowsi University of Mashhad, Mashhad, Iran. \\ 2. MSc Student, Ferdowsi University of Mashhad, Mashhad, Iran.
}

\begin{tabular}{|c|c|}
\hline $\begin{array}{l}\text { Use your device to scan } \\
\text { and read the article online }\end{array}$ & Citation: Amirfakhrian, M., \& Hasanneya, H. (2020). Spatial Analysis of Changes in Public Transport Passengers as a result \\
\hline 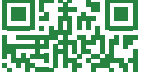 & $\begin{array}{l}\text { of the Corona Pandemic in the Mashhad Suburban Area. Journal of Sustainable Rural Development, 4(2), 149-162. https://doi. } \\
\text { org/10.32598/JSRD.4.2.4 }\end{array}$ \\
\hline 口124 & doil: https://doi.org/10.32598/JSRD.4.2.4 \\
\hline
\end{tabular}

\section{Article info:}

Received: 20 Feb. 2019

Accepted: 03 July 2020

\section{Keywords:}

Corona pandemic, Public transportation, Suburbs, Spatial analysis, Mashhad

\begin{abstract}
A B STRACT
Purpose: Public transport is one of the fields most affected by the Coronavirus pandemic which is of particular importance in the suburban areas due to daily transportation, as well as long trips and more dependence on public transport.

Methods: The present study attempts to investigate pre-COVID-19 and post-COVID-19 spatial changes in the volume of passengers in the Mashhad suburban area. This area includes 240 villages, 268 thousand population, and 754 bus stations. In this case, the documents, from Mashhad Bus Organization, were studied, the descriptive data for the volume of public transport passengers were obtained for each station separately; at the same time, a location database was created. The studied periods included pre-COVID-19 (March 2019-February 2020), and post-COVID-19 (March 2020-September 2020). Pre-COVID-19 and post-COVID-19 spatial variances were specified using spatial and classic statistical methods.
\end{abstract}

Results: The results indicated a significant difference between pre-COVID-19 and post-COVID-19 periods. On the other hand, the variances showed that, unlike other areas, in rural areas, far away from the west and northwest of Mashhad, the volume of post-Corona transportation has increased. A geographical regression model also indicated that among local factors, economic characteristics related to each village play the most significant role in explaining the changes; in some areas, it explains up to $63 \%$ of the changes.

Conclusion: Considering the demographic and economic structure of these areas and their strong dependence on public transport, techniques such as shutdown or reducing working hours, will lead to segregation of these villages. It is proposed that such studies, with a focus on the spatial analyses of the occurred changes, may contribute to managing public transport in order to redesign this area. 


\section{Introduction}

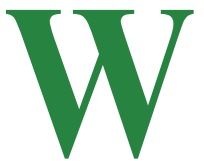

hile Coronavirus spread out on December 29, 2019, during just one month, it was considered as a public health emergency by the World Health Organization (WHO) and was recognized as a pandemic by March 2020 (Abdoli, 2020: 232-239). When Wuhan Municipal Health Commission reported 27 cases of viral pneumonia, the Coronavirus outbreak became a worldwide concern (Hou \& Chen, 2020: 841-848) and a threat for today's advanced world with all its technologies (Amiri, 2020: 358). Based on the World Health Organization statement (February 2020), the COVID-19 pandemic spread from Wuhan to 30 Chinese provinces and other countries. In a short period, some regions in Southeast Asia (Thailand, Singapore, Malaysia, Vietnam, Philippines, and Cambodia), East Asia (Japan, and South Korea), South Asia (India, Nepal, and Sri Lanka), West Asia (UAE, and Iran), Europe (Italy, Germany, England, France, and Spain), America (Canada, and US states), and even Australia experienced the disease outbreak (Alizadeh Fard \& Saffarinia, 2020: 131). In fact, the binomial nomenclature for Coronavirus is SARS-COV-2. The name stands for Severe Acute Respiratory Syndrome Coronavirus 2. The Latin word "Corona', meaning "crown" or "halo", refers to a crown-like appearance around the virus under a twodimensional electron microscope (Comprehensive and complete guide to Corona virus, 2020). Since the virus and effective ways to deal with it were unknown, in most countries addressing it depended on certain conditions (Zhu, Zhong, Zhang, \& Dong, 2020: 620-624). Also, its influence in urban environments varies psychologically (Irji Rad, 2020: 236), economically, socially (Asgari, Ghadami, \& Aminaei, 2020: 175), physically, and environmentally. Meanwhile, social and economic processes were exposed in a different way. Depending on implementation time and duration, these processes will emphasize general policy changes, key planning issues, such as strengthening public transport systems, and the aspects of urban design, such as closing streets and allocating them to bicyclists and pedestrians (Mogaji, 2020: $1-7)$. All conditions indicate that urban society is experimenting with methods to deal with these conditions, but the important point is that managing and controlling the situation requires accurate knowledge about these effects and consequences.

However, although, in human history, it is not the first time that a pandemic affects cities, there is limited scientific evidence of cities and pandemics before the COVID-19 outbreak. The researches on the previous pandemics in urban areas have focused mainly on some cases, such as the inequalities, making poor and marginalized groups more vulnerable to pandemics. In fact, this pandemic offers an unprecedented opportunity to understand how cities are affected by pandemics, as well as the measures required to minimize the effects and increase urban resilience when dealing with pandemics. This pandemic has led to unprecedented restrictions by many countries, such as travel restrictions and constraints on group gatherings, and has raised urban vulnerability to such diseases and interest in this issue. Among various issues, transportation may be the one most affected by COVID-19 (Mogaji, 2020: 1-7; Ho, Xing, Wu, \& Lee, 2021; Jenelius \& Cebecauer, 2020). It has made governments and officials apply large-scale traffic restrictions all over the world. Overall, COVID-19 has posed major challenges for transportation companies (Mitręga \& Choi, 2021: 1-7). The results of studies show that the impact of COVID-19 varies on various types of transportation. Regarding shipping and rail transport, some reports indicate that these items have been strengthened during this period (Gray, 2020: 239-243). For air transport, the decline was more than $80 \%$ in all regions of the world in May 2020 (Gianmarco, Gualini, Martini, Porta, \& Scotti, 2021: 1-17). Accordingly, the airline industry is the one suffering the consequences of the pandemic, although it may also be one of the major factors for the COVID-19 outbreak (Sun, Wandelt, \& Zhang, 2020). The results of some studies indicate that in populous cities, COVID-19 has led to a loss in non-motorized activities, but in sparsely populated cities, walking and cycling activities have increased (Zhang \& Fricker, 2021: 11-20). In addition, urban public transport has been highly affected by COVID-19 (Jenelius \& Cebecauer, 2020: 1-8). The results of the studies show that in some countries (such as Sweden), the public transport share has decreased by $60 \%$ during the COVID-19 outbreak (Ho, Xing, Wu, \& Lee, 2021: 4). On the other hand, air quality health index (AQHI), urban congestion level, and NO2 and CO concentration levels are highly correlated with COVID-19, while SO2 has no significant correlation with it (Tian, An, Chen, \& Tian, 2021: 270). However, it should be noted that public transport is one of the major ways to spread COVID-19 (Komla Junior Dzisi \& Akunor Dei, 2020: 1-5). Researches (Cochran, 2020: 1-10) indicate that the pandemic will cause a greater risk for people, particularly the handicapped; especially those without access to an automobile. The pandemic will exacerbate problems with access to transportation and other issues, with which the handicapped will face regularly, including the challenges for accessing safe and secure transportation, as well as modern communications for 
transportation, public health, problems receiving the required assistance, using transportation and conducting daily activities, from personal care to food preparation (Cochran, 2020: 1-10).

In this case, the perception of residents and citizens about public transport is important, because there is a risk that if the public transport sector is perceived as a poor mode of transportation in the post-pandemic situation, public transport will be recognized as an unsafe transportation mode, and this attitude may be established (Tirachini \& Cats, 2020: 10).

In the field of transportation and COVID-19, most of the studies have been published by American, Chinese, Japanese, and British authors (Kutela, Novat, \& Langa, 2021: 739), but the important point is that so far, there has been no spatial analysis of the spatial changes in the volume of passengers of the public transport sector during COVID-19 period. In foreign studies, some parts of COVID-19 and transportation aspects have been studied, while domestic studies have hardly dealt with this issue; in this sense, the present study may be innovative. Studies conducted in this field have addressed various aspects of COVID-19 impact on transportation. Among the most important studies in this field are increase in transportation costs (Mogaji, 2020), decrease in passengers' number (Orro, Novales, Monteagudo, Perez-Lopez, \& Bugarin, 2020), (Shakibaei, de Jong, Alpkökin, $\&$ Rashidi, 2021), decrease in the number of transportation modes (Mogaji, 2020), the turnover of transportation companies (Ho, Xing, Wu, \& Lee, 2021), the behavioral change of passengers from monthly tickets to single tickets (Jenelius \& Cebecauer, 2020), the hygiene and safety of transportation environments (Shen et al., 2020), forecasting and simulating (Guan et al., 2020) the changes, being affected by factors such as land use and socio-demographic characteristics (Bian et al., 2021), high COVID-19 impact on this field (Abu-Rayash \& Dincer, 2020), (Cui et al., 2021), travel behavior patterns (Maria Barbieri et al., 2020), factors affecting the intensity of changes in the use of transportation (Hu \& Chen, 2021), and observing hygienic protocols (Komla Junior Dzisi \& Akunor Dei, 2020).

Among the important areas in the field of transportation studies are suburban areas and their residents, which are of great importance for various reasons, such as high dependence on public transport, daily urban trips, and long trip time. In this sense, Mashhad is a special instance. The Mashhad suburban area includes an area of $1686 \mathrm{~km} 2$ (5.6 times larger than Mashhad) with 240 villages, where a population of 268 thousand people live. This area is supported by Mashhad public transport fleet through 754 bus stations. However, after the COVID-19 outbreak and imposing restrictions on the public transport system, this area has been particularly affected. Knowing about the transportation volume in this area pre-COVID-19 and post-COVID-19, identifying areas, identifying highly affected areas, displaying spatial variances in this field, and identifying effective local factors may be a great help to provide appropriate planning for this area. Using spatial methods and analyses, the present study attempts to achieve the above objectives in the Mashhad suburban area and its villages.

\section{Literature Review}

COVID-19 pandemic has persuaded governments and officials around the world to impose large-scale restrictions on transportation. The results of studies indicate high vulnerability of public transport compared to other options, and this reduction may be due to official limitations or passengers' choices. The stations of public transport and vehicles are known as a high-risk environment for spreading COVID-19, due to limited physical space, the plenty of surfaces, and limited passengers testing; at the same time, some countries, including Sweden, have replaced restrictions by recommendations and attempted to prevent the decline of public transport status and maintain hygienic safety (Jenelius \& Cebecauer, 2020: 1-8). Studies in the field of public transport and COVID-19 pandemic are still very limited; hence, one of the challenges in this field is to address a new issue. During the COVID-19 pandemic, various parameters may be considered in public transport; for example, Tan and Ma (2020) showed occupation, time for walking from home to the nearest subway station, and infection risk indices for a private car and public transport; Mogaji (2020), Orro, Novales, Monteagudo, Perez-Lopez, \& Bugarin, (2020), and Tian, An, Chen, \& Tian, (2020) indicated the reduction of transportation modes, the impact on the number of passengers, the impact on fuel consumption and air pollution, the behavioral change of passengers, the increase of cost and so on, respectively. Regarding suburban areas and their rural settlements, this issue can include all of the mentioned factors or a combination of them. Thus, the COVID-19 pandemic has changed the situation of human settlements economically, socially, demographically, physically, and ecologically. At this scale, suburban areas are among the important residential areas. On the other hand, among the issues affected by COVID-19 are transportation and its various forms, of which public transport is one of the implications. Studies have identified variables such as the num- 
ber of passengers, transportation costs, travel patterns, and transportation modes, as the most important issues in this field. In the case of suburban settlements, which a major part of their transportation is dependent on public transport, it may have different effects (Figure 1).

\section{Methodology}

Considering the research question, the research method was a combination of descriptive and analytical methods. The research variables included the number of passengers, and entering the public transport stations in the Mashhad suburban area during pre-COVID-19 and postCOVID-19 months. The analytical scale was also based on the bus stations located in this area. In this case, first, the bus stations of the Mashhad suburban area (including 754 stations) were identified, and their spatial map was provided. Then, the data for passenger transportation volume in each station during two periods, pre-CO-
VID-19, from March 2019 to February 2020, and postCOVID-19, from March 2020 to September 2020, were obtained in Excel format by referring to Mashhad Bus Organization. The obtained data were entered into the location database of stations; then, the spatial variances for pre-COVID-19 and post-COVID-19 periods were measured using classic and spatial statistical models. The work in this field was based on using spatial techniques such as interpolation, Gi spatial density and statistics, and classic statistical tests such as the one-sample $\mathrm{t}$-Test and paired t-Test. Then, local factors affecting the pre-COVID-19 and post-COVID-19 changes of passengers of the stations were measured by a spatial regression model to determine the effect of each local factor on the changes caused by the COVID-19 outbreak. The results of this section were correlated with the descriptive and documentary findings. Finally, the results were summarized and concluded. The following figure shows the process of the study.

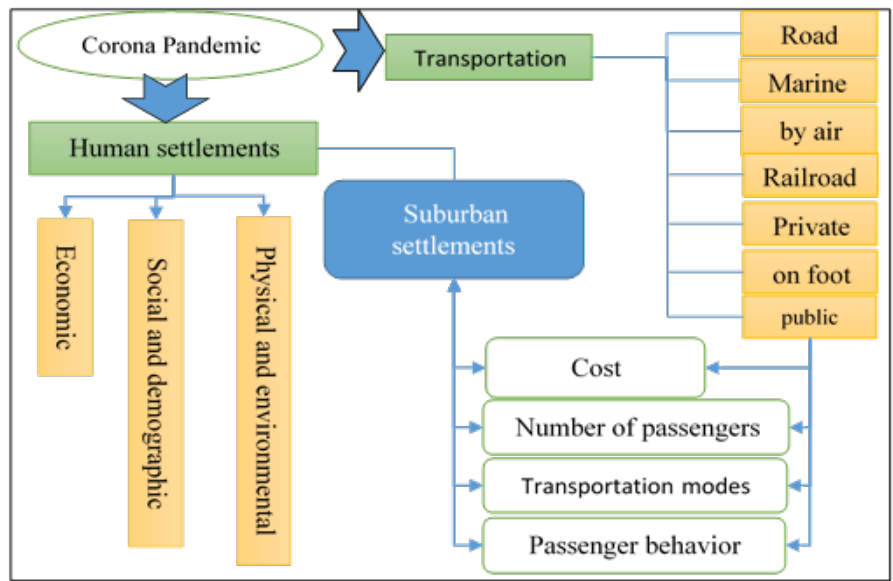

Figure 1. Conceptual model of research

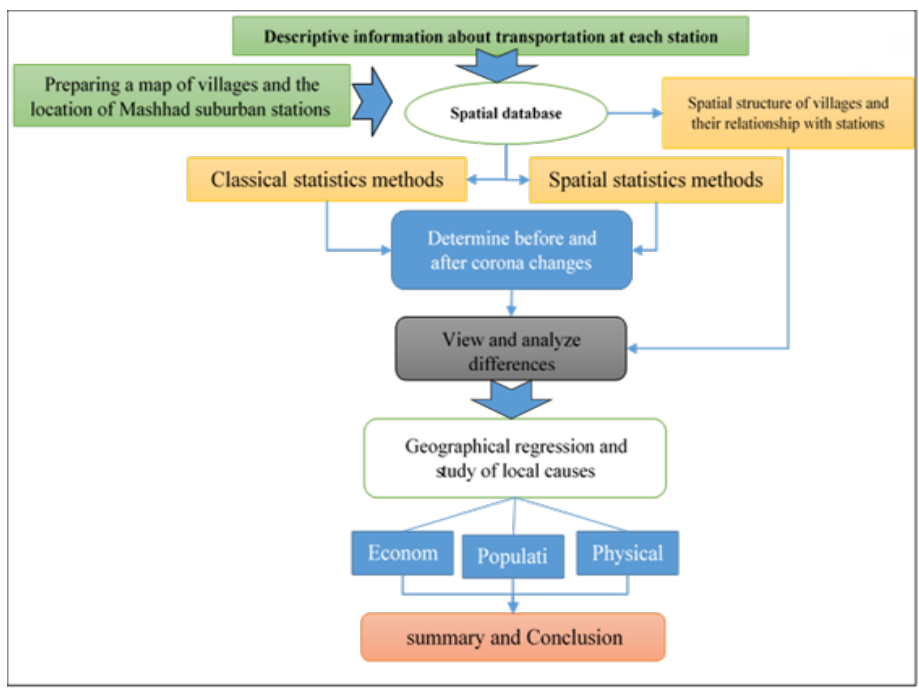

Figure 2. Research process 


\section{Findings}

\section{The Mashhad suburban area}

This area equal to $1686 \mathrm{~km}^{2}$ (5.6 times larger than Mashhad), includes a region between Mashhad and its suburbs. In terms of land use, this area includes agricultural, garden, industrial and rural regions formed over many years. 240 villages were located in this region with a 268589 population and an average of 1119 people, showing a population density equal to a $8 \mathrm{~km}^{2}$ village (Table 1).

The settlement pattern for the villages located in this area may be considered as a linear pattern in some regions, mainly located around transportation routes.
These routes can be classified into 9 main routes, including Neyshabour, Seyedi, Mayamey, Tabarsi, Esmailabad and Khin-e-Arab, Quchan Old Road, Quchan New Road, and Torqabeh and Shandiz routes.

Public transport stations in the Mashhad Suburban Area

There are 754 stations in this region, $20 \%$ of the total public transport stations, covered by Mashhad bus organization. On average, each station is supported by three lines; in total, 2255 bus lines stop at the stations of this region. On average, the villages located in this region are $2 \mathrm{~km}$ away from the stations. On average, there are three stations in front of each village (Table 2 and Figure 3).

Table 1. Villages located in the Mashhad suburban area based on population classes

\begin{tabular}{cccc}
\hline The size of the village & Number & Population & population Average \\
\hline Less than 500 (small villages) & 150 & 16459 & 109 \\
500 to 1000 (medium-sized villages) & 28 & 21096 & 353 \\
More than 1000 & 62 & 231034 & 2685 \\
Total & 240 & 2689 & 1119 \\
\hline
\end{tabular}

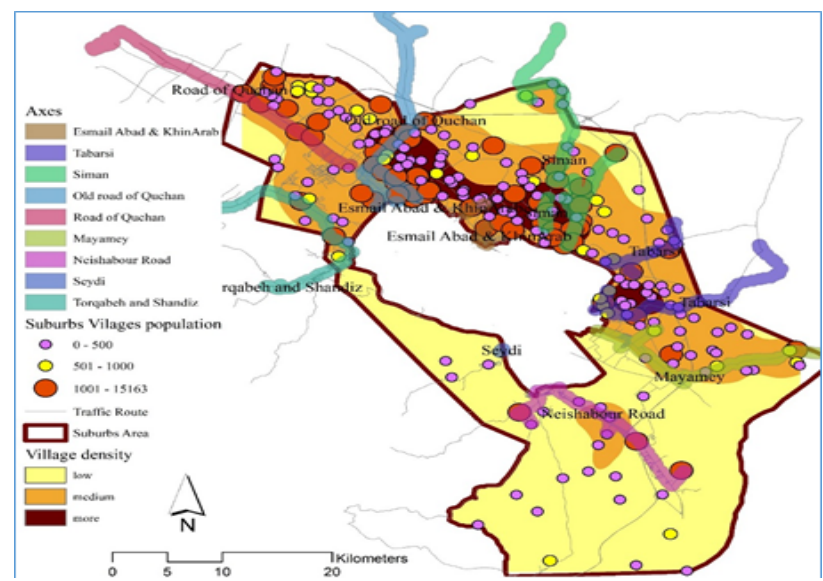

Figure 3. The Mashhad suburban area and villages in terms of population

Table 2. Villages located in the Mashhad suburban area and the main axes and stations related to each

\begin{tabular}{|c|c|c|c|c|c|c|c|c|c|c|}
\hline Main axes & 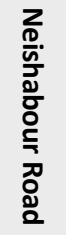 & 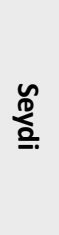 & 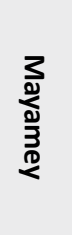 & $\begin{array}{l}\vec{y} \\
\underline{\underline{g}} \\
\underline{\underline{w}}\end{array}$ & 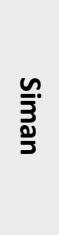 & 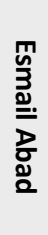 & 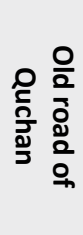 & 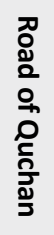 & 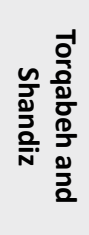 & 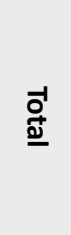 \\
\hline Number of villages & 14 & 5 & 12 & 28 & 43 & 19 & 45 & 23 & 13 & 202 \\
\hline Number of stations & 64 & 5 & 78 & 105 & 190 & 35 & 169 & 35 & 73 & 754 \\
\hline Number of lines & 171 & 22 & 269 & 236 & 729 & 55 & 583 & 36 & 154 & 2255 \\
\hline
\end{tabular}


Spatial analysis of pre-COVID-19 and post-COVID-19 passengers transported by public transport fleet in suburban villages

The investigation of statistics on the volume of passengers transported in the stations of the bus fleet in the Mashhad suburban area indicates that 1327342 people are transported per month in the stations of this area; based on the number of stations, it represents the monthly average of 1760 people for each station, a daily average of 59 people per station. After the COVID-19 outbreak in Mashhad in February 2020, significant changes could be seen in the volume of public transport passengers in the Mashhad suburban area. Examining the statistics on the volume of post-COVID-19 transported passengers in the bus fleet stations of Mashhad suburban area shows that 743021 people are transported monthly in the stations of this region; based on the number of stations, it represents an average of 985 people per station, this number is an average of 33 people per day for each station. The following diagram shows the changes of pre-
COVID-19 and post-COVID-19 passangers transported in the Mashhad suburban area stations.

Studying spatial trends in this area shows that before the COVID-19 outbreak, parts of the north of Mashhad including Siman Road and its villages, as well as the east of Mashhad including the Mayamey and Sarakhs Roads and their villages have the highest volume of transportation. In this area, post-COVID-19 spatial trends are also similar to pre-COVID-19 trends, so some parts of the north of Mashhad including Siman Road and its villages, as well as the east of Mashhad including the Mayamey and Sarakhs Roads and its villages, have the highest volume of transportation (below map).

The results of the one-sample t-Test indicate that there is a significant difference between the volume of passengers per station and pre-COVID-19 average value (1760) and post-COVID-19 (985) average value. The variance represents the different situations of the stations in terms of passenger volume.

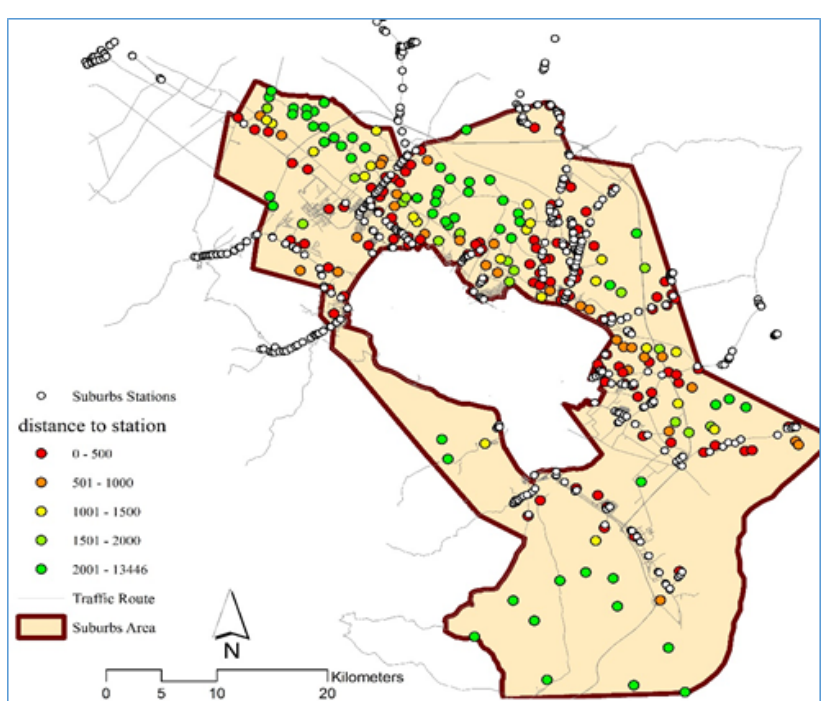

Figure 4. Location of suburban villages of Mashhad based on distance from bus stations
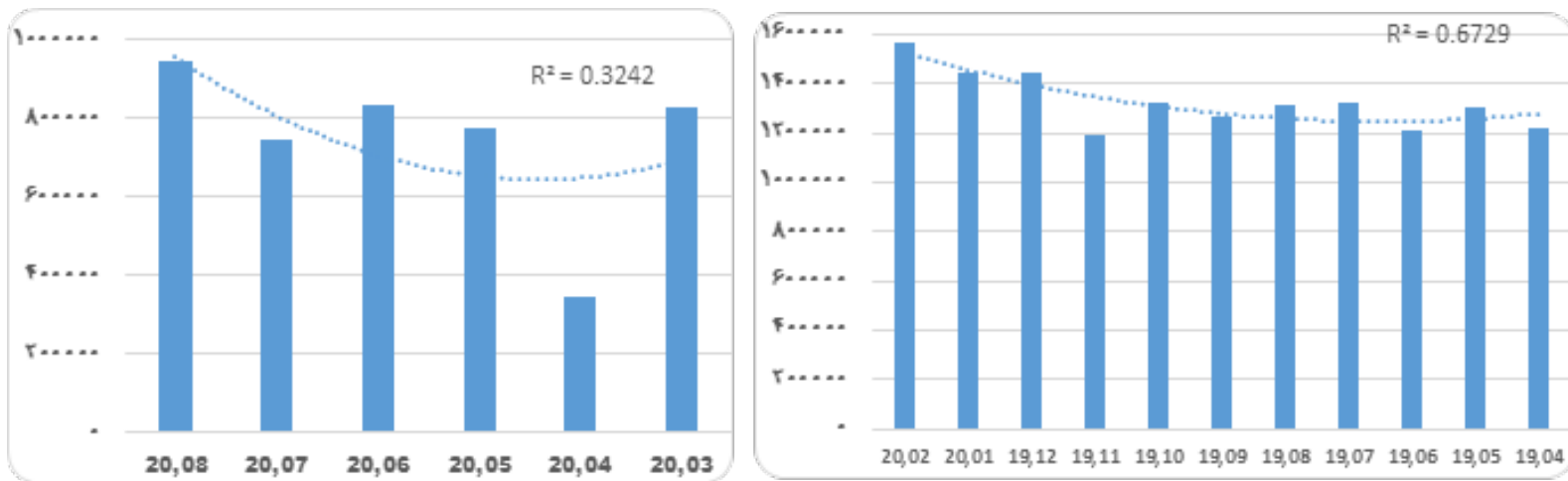

Figure 5. Changes in the number of passengers transferred in the suburban stations of Mashhad before (right) and after the Corona (left) by month 

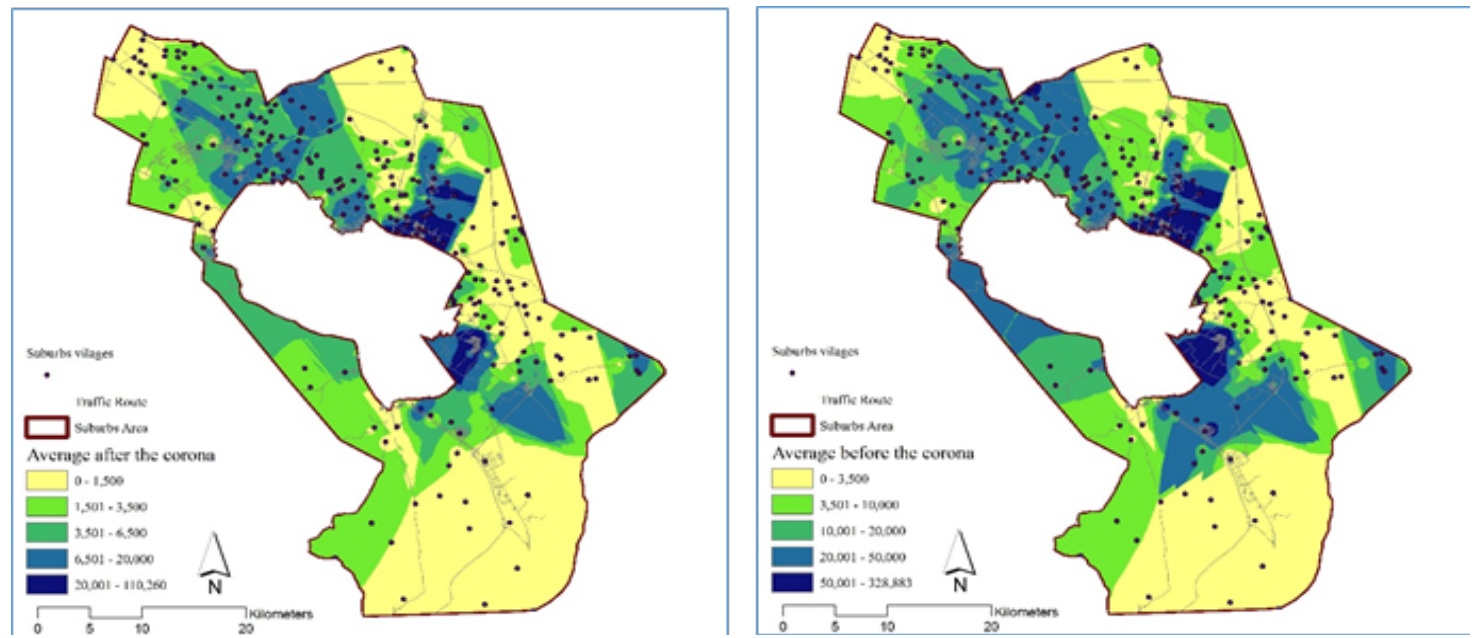

Figure 6. Spatial distribution of the population of public transport users in the Mashhad suburban area before and after Corona

Table 3. Significance level of the monthly number of passengers per station compared to the average, based on the one-sample t-test

\begin{tabular}{|c|c|c|c|c|c|c|}
\hline & \multicolumn{6}{|c|}{ Test Value $=1760$} \\
\hline & \multirow{2}{*}{$\mathbf{t}$} & \multirow{2}{*}{ df } & \multirow{2}{*}{ Sig. (2-tailed) } & \multirow{2}{*}{ Mean Difference } & \multicolumn{2}{|c|}{ 95\% Confidence Interval of the Difference } \\
\hline & & & & & Lower & Upper \\
\hline Before & .000 & 753 & 1.000 & .000 & -3377.99 & 3377.99 \\
\hline \multirow{2}{*}{ After } & \multicolumn{6}{|c|}{ Test Value $=985$} \\
\hline & .000 & 753 & 1.000 & .000 & -981.06 & 981.06 \\
\hline
\end{tabular}

It means that the use of stations and the volume of passengers do not follow the same pattern; in this sense, the stations are different from each other. This difference is seen pre-COVID-19 and post-COVID-19.

A more detailed study of station differences in terms of the number of passengers and spatial variances using Gi analytical index indicates that before the COVID-19 outbreak, there was a significant difference in the number of passengers between suburban stations in only four regions of Siman Road and Esmailabad Road in the north, Mayamy Road in the east, and Torqabeh Road in the west, and there was no significant difference in other stations. However, after the COVID-19 outbreak, this variance can be seen only in two regions of Siman Road in the north and Mayamy Road in the east, and there is no significant difference in other stations. In this sense, some pre-COVID-19 and post-COVID-19 spatial variances are observed (Figure 7).

Pre-COVID-19 and post-COVID-19 changes in the volume of passengers
As it was mentioned, studying the volume of passengers in Mashhad suburban stations and their overall changes indicate a decrease in the number of passengers in all post-COVID-19 months. Paired two-sample t-Test shows a significant difference between pre-COVID-19 and post-COVID-19 transported passengers (below table).

Pre-COVID-19 and post-COVID-19 spatial variances indicate interesting points:

1- Regions with post-COVID-19 increased passenger volume in the public transport fleet: These regions have a low passenger volume, but the trend of their changes indicates an increase in the number of passengers after the COVID-19 outbreak. Also, these regions are further apart from the Mashhad urban area. In total, this difference also shows an increase of up to 4,000 people. These regions include villages located in Quchan Road in the northwest and Neyshabour Road in the southeast. 
2- $\quad$ Regions with a significant decrease in the passenger volume of transportation fleet after the $\mathrm{CO}$ VID-19 outbreak: These areas include regions with a high volume of passengers, including Siman Road in the north of Mayamy Road in the east of Mashhad.
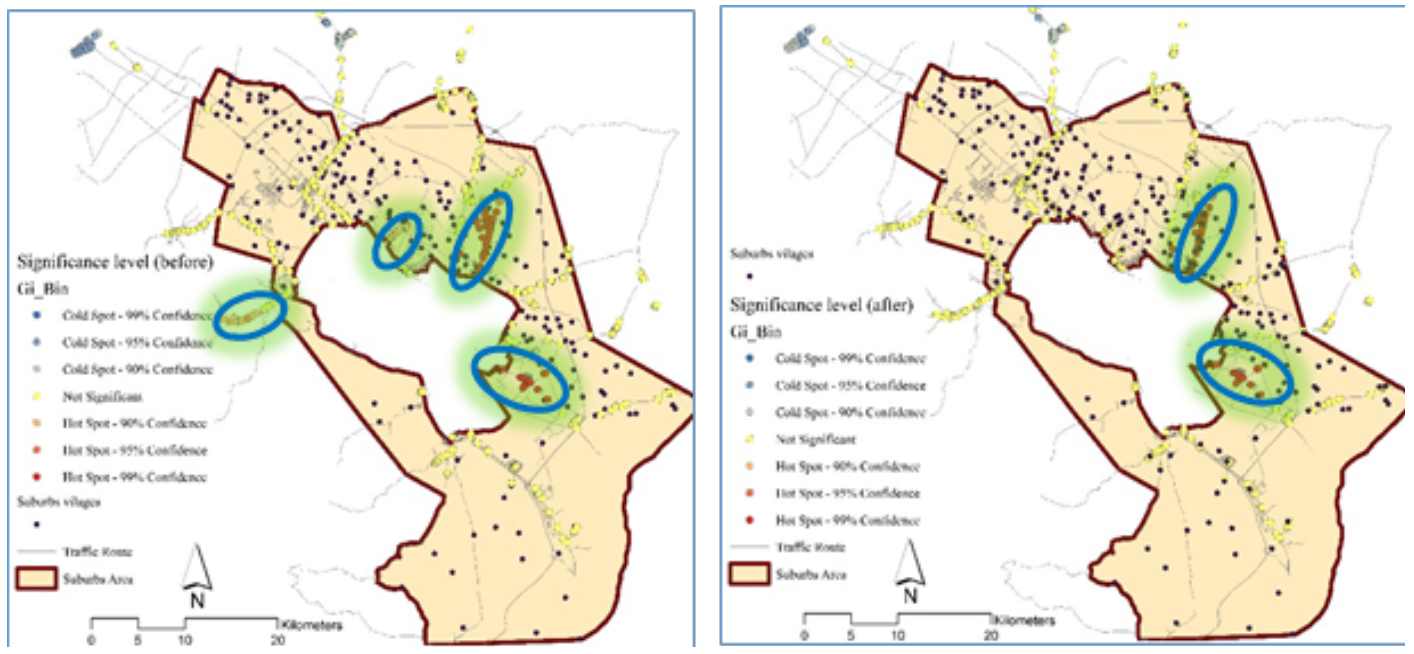

Figure 7. Assessment of the significance level of passenger volume at bus stations before (right) and after the Corona (left) based on the general index Gi

Table 4. Significance level of difference between public transport passengers of bus stations in the Mashhad suburban area before and after the Corona pandemic according to the pairwise t-test

\begin{tabular}{|c|c|c|c|c|c|c|c|c|}
\hline & \multicolumn{5}{|c|}{ Paired Differences } & \multirow{3}{*}{$\mathbf{t}$} & \multirow{3}{*}{ df } & \multirow{3}{*}{$\begin{array}{c}\text { Sig. } \\
\text { (2-tailed) }\end{array}$} \\
\hline & \multirow{2}{*}{ Mean } & \multirow{2}{*}{$\begin{array}{l}\text { Std. Devia- } \\
\text { tion }\end{array}$} & \multirow{2}{*}{$\begin{array}{l}\text { Std. Error } \\
\text { Mean }\end{array}$} & \multicolumn{2}{|c|}{$\begin{array}{l}\text { 95\% Confidence Interval of the } \\
\text { Difference }\end{array}$} & & & \\
\hline & & & & Lower & Upper & & & \\
\hline Before \& After & 12895.374 & 34301.836 & 1249.199 & 10443.047 & 15347.702 & 10.323 & 753 & .000 \\
\hline
\end{tabular}

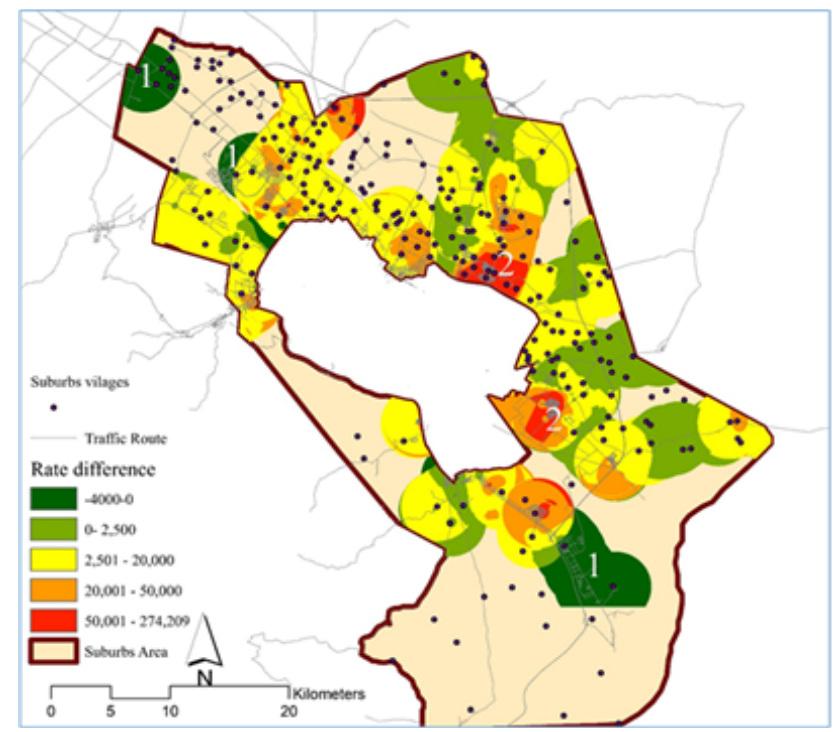

Figure 8. Passenger volume difference of each station in the Mashhad suburban area before and after the Corona pandemic 
Studying spatial changes in terms of major routes of the area shows that most of the changes in the volume of passengers are those of Siman Road and Esmailabad and Khin-e- Arab, decreased by an average of 21 thousand people per month. On the other hand, the least changes can be seen in Tabarsi Road, with a monthly average decrease of 3680 people (Table 5 and Figure 9).

\section{Factors influencing the changes}

As the findings indicated, COVID-19 has led to a significant change in the volume of public transport passengers in the settlements around Mashhad. A spatial regression analysis was used to understand the local factors affecting the intensity of these changes. It seems that the socio-demographic, economic and physical characteristics of the villages can be affected differently by these changes. Thus, it is necessary to consider some variables, with the mentioned aspects, to form a spatial regression model. However, due to the limited data for three variables of village size, in terms of population, the number of men and economic actors for each village, and each village distance to the station, were considered as selective variables for the mentioned aspects to determine the most relevant changes.

Table 5. Volume of bus passengers and their changes in the Mashhad suburban area by axis and village

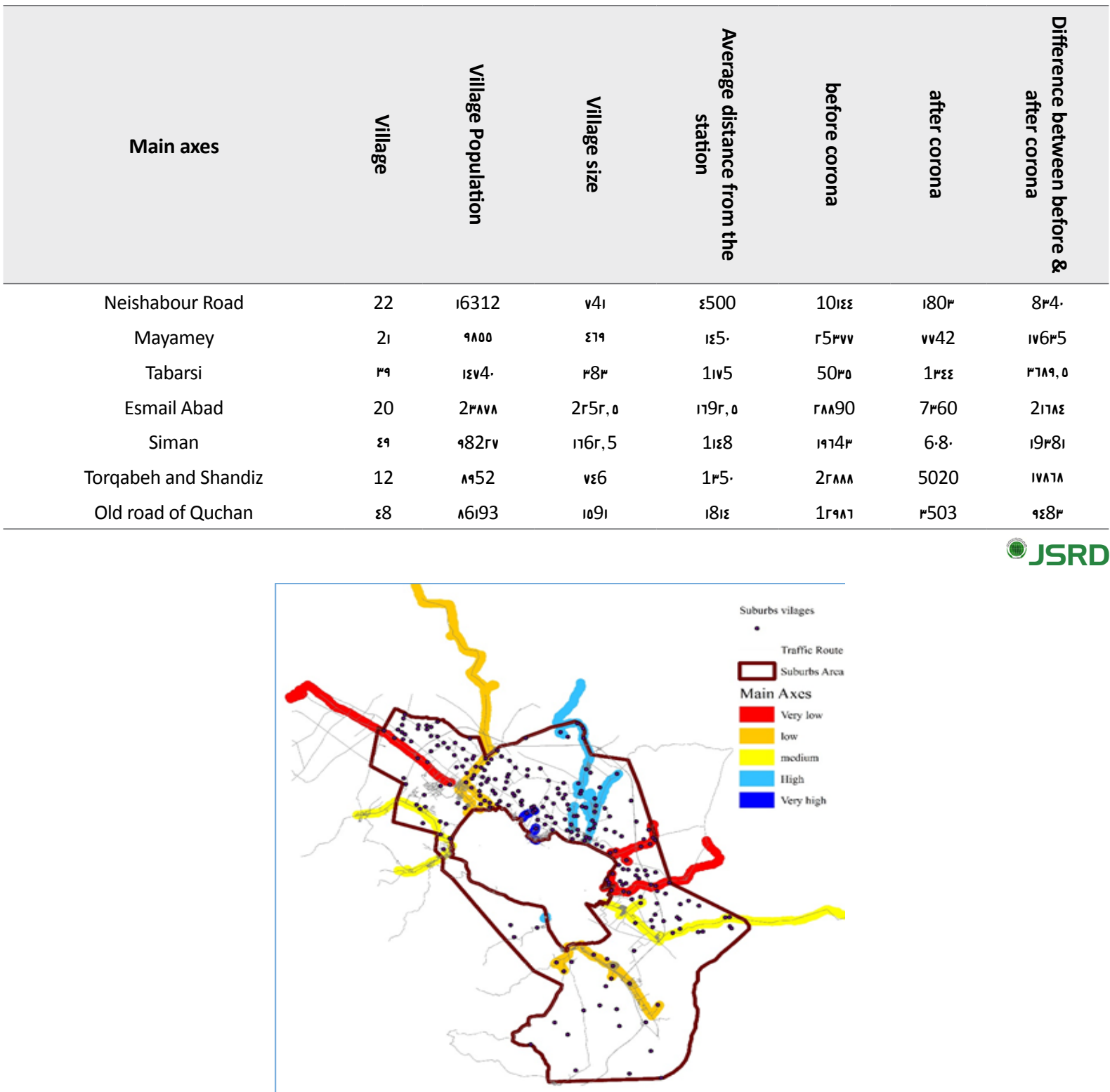

Figure 9. Spatial changes in the volume of bus passengers in the Mashhad suburban area according to the main axes and the village 


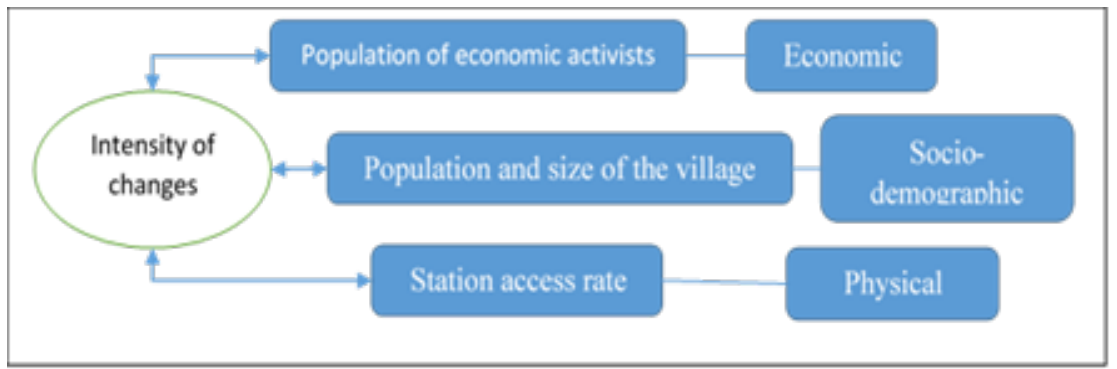

The results of impact and correlation indicate that among the mentioned variables, the population of economic actors has the most correlation with the intensity of changes, that is, the economic effects due to COVID-19 have the most effect on suburban villages. The below table illustrates this issue. As it can be seen, regarding other variables, the level of their significance is not confirmed. Also, in this table, the values of VIF (variance inflation factor) are less than 7.5 , indicating the rejection of the redundancy hypothesis and multilinearity of variables.

Based on the above diagram and table (for impact factor), it is clear that the variable of economic actors has a reverse role. In other words, as the number of economic actors increases in rural areas, the remainder of the post-
COVID-19 transportation volume difference decreases Overall, the coefficient of determination calculated for the independent variables is $0.41 \%$, showing that $41 \%$ of the correlations between the independent and dependent variables are explained in this model. The variance between the villages shows an explanatory value between $1.46 \%$ to $63.3 \%$, indicating the difference and impact, and showing that the impact varies greatly between the villages, depending on their location (Figure 11).

Considering the above picture, it is clear that in the northern villages of Mashhad, a regression model can be strongly explained, while in the western and northwestern villages of the above model, the percentage of explanation is low and very low.

Table 6. Results of spatial regression regarding local variables affecting the volume of passengers in the Mashhad suburban area

\begin{tabular}{cccc}
\hline Variable & Impact factor & Significance level & Variance Inflation (VIF) \\
\hline Constant & $11391.50-$ & 0.000341 & -- \\
Economic activists & $8.1-$ & 0.000 & 1.84 \\
The size of the village & 043 & 0.41 & 1.07 \\
Distance to the station & 659.4 & 0.71 & 1.82 \\
\hline
\end{tabular}

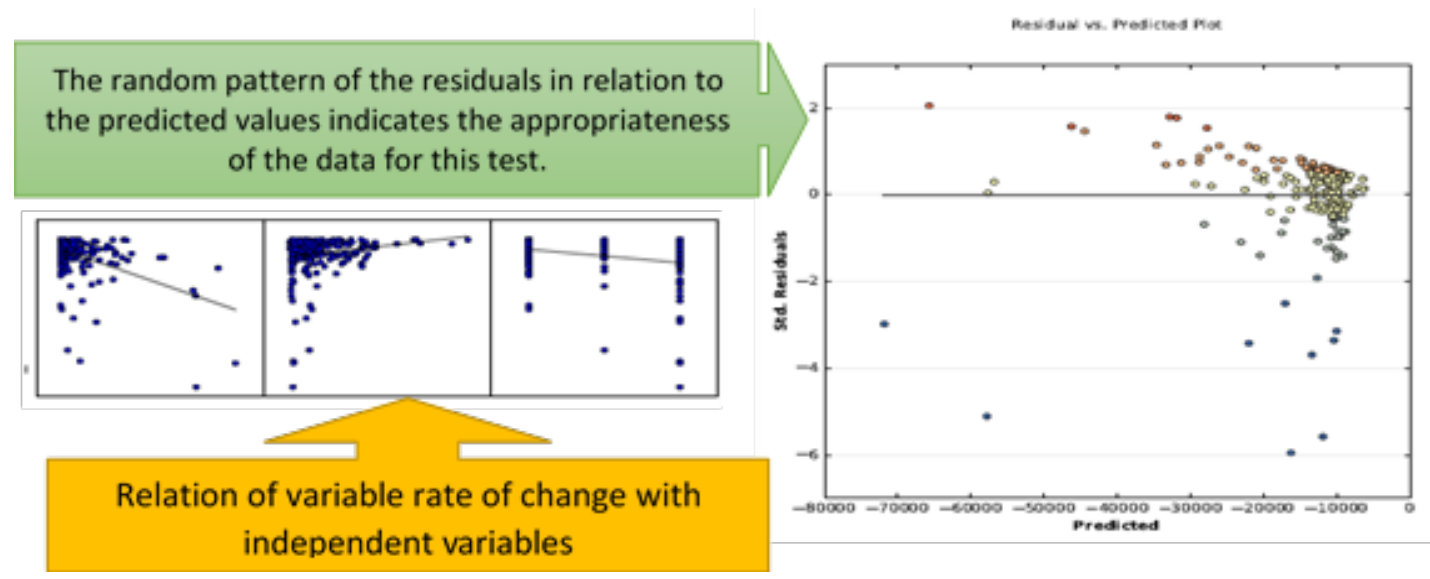

Figure 10. Correlation of independent variables with the dependent variable and residual pattern of predicted values obtained from geographical regression 


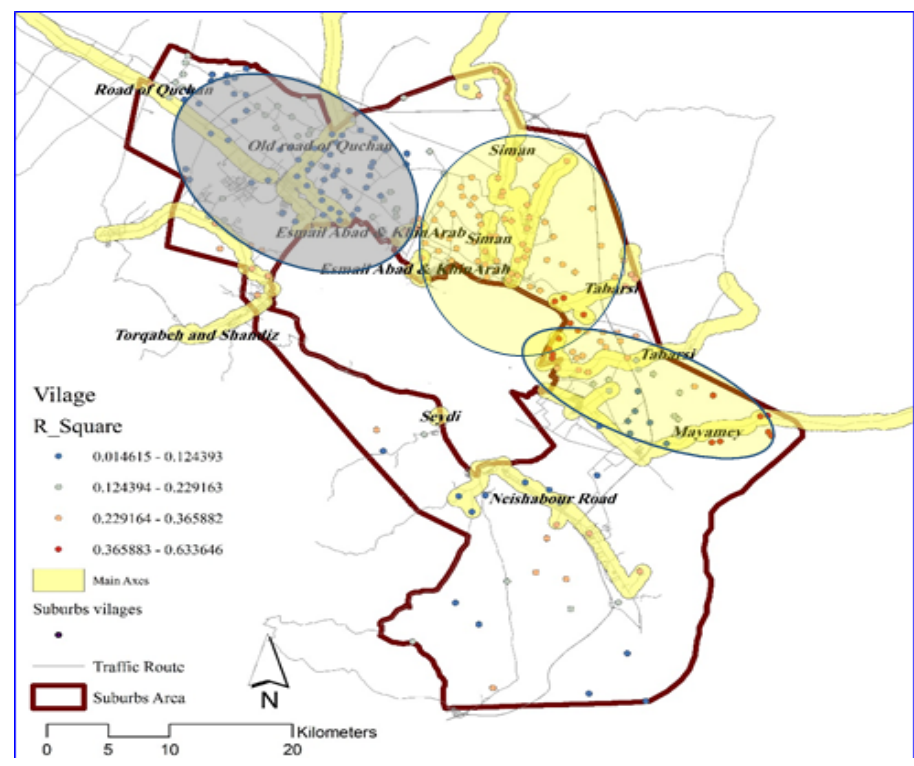

Figure 11. R. Square index obtained from spatial regression in the study area by village

\section{Discussion}

The results indicate the high area and population of the Mashhad suburban area and its villages, which indicates high demand, on the one hand, and high transportation, on the other hand. The average population of 1120 people for the villages of this area represents the pattern of large-scale villages and their potential for the transportation of a high population. The linear pattern of villages and their average short distance to bus stations is the position of public transport in this area. Post-COVID-19 significant decline in the population using public transport in this area indicates the impact of the pandemic on the transportation in this area. Complementary findings also show that, on the contrary, in some areas, after the pandemic outbreak, the use of public transport has increased. Since the villages are located further apart from Mashhad and include a low volume of passengers, it can be concluded that the COVID-19 outbreak has had less impact on this area. The results of spatial regression indicated that among the population of rural economic actors, the population size of the village and the distance of each village to the station, economic characteristics have the most impact on explaining the changes; this indicates that economic goals and aspects are the main reasons for the relationship between these villages and Mashhad. The spatial changes of the explanation coefficient for each village indicated that a regression model can be highly explained for Mashhad northern villages, while for the western and northwestern villages of the above model, the percentage of explanation is low and very low. In other words, for the villages of the northern regions, the changes in public transport can be properly explained by the economic factor. In a sense, in the villages of this area, the impact of economic aspects, due to the number of the labor force, can be well confirmed, but in Mashhad northwestern and western villages, the changes in the transportation of passengers do not show a proper correlation with this variable. It can be concluded that Mashhad western and northwestern villages have had less economic relations with Mashhad than the northern villages.

Theoretical achievements: In recent years, no factor has decreased the number of public transport users in the studied area as much as COVID-19. This issue is consistent with the findings of (Abu-Rayash \& Dincer, 2020). Due to the shutdown of Mashhad public transport for several months, the transportation costs of residents have increased, confirming the findings of (Mogaji, 2020). Findings of (Orro, Novales, Monteagudo, Perez-Lopez, \& Bugarin, 2020) and (Shakibaei, de Jong, Alpkökin, $\&$ Rashidi, 2021) also show the decrease of passengers in the studied area due to the COVID-19 outbreak. The decrease of passengers and financial volume of transportation companies in the studied area are also shown by the findings of (Ho, Xing, Wu, \& Lee, 2021). Among the studied factors, economic parameters are more correlated with the user changes, supporting the findings of (Bian et al., 2021). On the other hand, the findings of (Hu \& Chen, 2021) show that the highest decrease in the passengers of public transport is that of the commercial regions of cities. In the studied area, it is not correlated with this issue due to its social and economic characteristics. However, based on the results, the highest decrease is that of the routes with the most economic actors, com- 
pared with suburban areas, which confirms the results of the study by (Hu \& Chen, 2021).

Practical recommendations: According to the findings, practical recommendations are as follows:

- Due to ahigh dependence of the residents on public transport, adopting methods such as shutdown or decreasing service hours may make it difficult for people living in this area to access job opportunities. On the other hand, in this area, the trip duration is mostly longer than the average, so the protocols related to shutdown or restrictions are not a proper recommendation, especially for the residents of this area. Also, this solution will lead to excessive isolation of this area; it will also have a negative impact on its sociability.

- In addition, as the findings of the study indicated, public transportation may be one of the major centers for the pandemic outbreak. Hence, the requirement for constant care and monitoring transportation services is important.

- In this field, the lack of internal studies is quite evident, while the transportation sector is among the most affected ones by COVID-19. Thus, the requirement for paying attention to this issue is of particular importance. It is also necessary to undertake these studies based on spatial analyses and in the context of a geographical database to achieve a more accurate picture of developments and changes.

- COVID-19 provides an opportunity to redesign urban transportation plans, particularly in suburban areas, for more stability.

- It is essential to minimize the negative effect on the perception of residents of public transport because it will drastically decrease its use in the future and lead to a loss of public trust.

- For other researchers, attempting to study in this field, it is suggested that some parameters, such as trip reason, trip duration, the number of trips, and trip hours be carefully investigated in the process of data collection.

This study attempted to show the spatial changes in the volume of public transport passengers in the Mashhad suburban area. The results of using spatial and classical statistics in the form of tables, diagrams, and maps show a significant difference in the specific volume and ranges of pre-COVID-19 and post-COVID-19 public transport situations, in a way that the monthly average for the number of passengers has decreased from 1760 to 985 people. On the other hand, some significant spatial variances can be seen between some parts of the north of Mashhad and other parts. The spatial representation of variances indicates that, in spite of the general pattern of passengers decrease in some areas, especially the west and northwest, the volume of passengers has increased after the COVID-19 outbreak. These regions have mainly low passengers and are located further apart from Mashhad. The findings show that among the local factors, the structure and economic population of the villages have the greatest effect on explaining the changes in the volume of passengers, and also indicate that most of these villages are related to Mashhad, based on some economic characteristics.

In fact, the present research is novel due to its subject and way of looking at the problem, as well as the scope of the study, so that there is no spatial analysis of the changes in public transport during the COVID-19 outbreak in suburban areas. This issue is of particular importance due to the strong dependence of the population in this area on daily transportation.

The present study showed that transportation patterns in the target society to some extent follow a general trend. In some cases, it showed slightly different results. Findings may help bus management to provide a better service to the Mashhad suburban area in order to organize a new form of urban-rural relation in these areas. This requires special attention and contribution. Also, the most important limitation of the study, which may be considered by other researchers in future studies, is the lack of access to the data regarding the trip reason, trip duration, and trip time before and after the COVID-19 outbreak, which will provide a more accurate picture of the changes.

\section{Acknowledgements}

This research did not receive any specific grant from funding agencies in the public, commercial, or not-forprofit sectors.

\section{Conflict of Interest}

The authors declared no conflicts of interest. 


\section{References}

Abdoli, N. (2020). Predicting general health based on individual variables, self-efficacy and anxiety in employees (students and non-students) Medical staff of Covid patients 19. Educational Psychology of Allameh Tabatabai University, 16 (56).

Abu-Rayash, A., \& Dincer, I. (2020). Analysis of mobility trends during the COVID-19 coronavirus pandemic: Exploring the impacts on global aviation and travel in selected cities. Energy Research \& Social Science 68.

Alizadeh Fard, S., \& Saffarinia, M. (2020). Predicting mental health based on anxiety and social correlation due to coronary heart disease. Social Psychology Research, 36, 129-141.

Amiri, P. (2020). The role of e-health at the beginning of the Corona crisis: A systematic review of documentation. Health and Biomedicine Informatics Medical Informatics Research Center, 6 (4), 358-367.

Asgari, M., Ghadami, A., \& Aminaei, R. (2020). Covid disease dimensions and its psychological damage: A systematic review study. Journal of Educational Psychology, Allameh Tabatabaei University, 16, 56, 167-177.

Bian, Z., Zuo, F., Gao, J., Chen, Y., Chandra Pavuluri Venkata, S., Duran Bernardes, S., ... Wang, J. (2021). Time lag effects of COVID-19 policies on transportation systems: A comparative study of New York City and Seattle. Transportation Research Part A: Policy and Practice 145, 269-283.

Cochran, A. (2020). Impacts of COVID-19 on access to transportation for people with disabilities. Transportation Research Interdisciplinary Perspectives 8.

Comprehensive and complete guide to Coronavirus. (2020, March). Retrieved from The clinic: https://www.darmankade.com/blog/corona-virus/

Cui, Q., He, L., Liu, Y., Zheng, Y., Wei, W., Yang, B., \& Zhou, M (2021). The impacts of COVID-19 pandemic on China's transport sectors based on the CGE model coupled with a decomposition analysis approach. Transport Policy 103, 103-115.

Gianmarco, A., Gualini, A., Martini, G., Porta, F., \& Scotti, D. (2021). The disruptive impact of COVID-19 on air transportation: An ITS econometric analysis. Research in Transportation Economics.

Gray, R. S. (2020). Agriculture, transportation, and the COVID-19 crisis. Canadian Journal of Agricultural Economics 68 (2), 239-243

Guan, L., Prieur, C., Zhang, L., Prieur, C., Georges, D., \& Bellemain, P. (2020). Transport effect of COVID-19 pandemic in France. Annual Reviews in Control 50, 394-408.

Ho, S.-J., Xing, W., Wu, W., \& Lee, C.-C. (2021). The impact of COVID-19 on freight transport: Evidence from China. MethodsX 8,4 .

Hou, C., \& Chen, J. (2020). The effectiveness of quarantine of Wuhan city against the Corona Virus Disease 2019 (COVID-19): A well-mixed SEIR model analysis. JOURNAL OF MEDICAL VIR, 841-848

Hu, S., \& Chen, P. (2021). Who left riding transit? Examining socioeconomic disparities in the impact of COVID-19 on ridership. Transportation Research Part D: Transport and Environment 90.
Irji Rad, A. (2020). The psychological effects of the virus Covid 19 staff in research, education and extension in time of emergency (quarantine). Educational Psychology, Allameh Tabatabai University, 16, 56, 229-237.

Jenelius, E., \& Cebecauer, M. (2020). Impacts of COVID-19 on public transport ridership in Sweden: Analysis of ticket validations, sales and passenger counts. Transportation Research Interdisciplinary Perspectives, 8, 1-8 doi:10.1016/j. trip.2020.100242

Komla Junior Dzisi, E., \& Akunor Dei, O. (2020). Adherence to social distancing and wearing of masks within public transportation during the COVID 19 pandemic. Transportation Research Interdisciplinary Perspectives 7.

Kutela, B., Novat, N., \& Langa, N. (2021). Exploring geographical distribution of transportation research themes related to COVID-19 using text network approach. Sustainable Cities and Society, 739 .

Maria Barbieri, D., Lou, B., Passavanti, M., Hui, C., Antunes Lessa, D., Maharaj, B., . . . Adomako, S. (2020). A survey dataset to evaluate the changes in mobility and transportation due to COVID-19 travel restrictions in Australia, Brazil, China Ghana, India, Iran, Italy, Norway, South Africa, United States. Data in Brief 33.

Mitręga, M., \& Choi, T.-M. (2021). How small-and-medium transportation companies handle asymmetric customer relationships under COVID-19 pandemic: A multi-method study. Transportation Research Part E: Logistics and Transportation Review 148, 1- 7

Mogaji, E. (2020). Impact of COVID-19 on transportation in Lagos, Nigeria. Transportation Research Interdisciplinary Perspectives, 6, 1-7.

Orro, A., Novales, M., Monteagudo, A., Perez-Lopez, J.-B., \& Bugarin, M. (2020). Impact on City Bus Transit Services of the COVID-19 Lockdown and Return to the New Normal: The Case of A Coruña (Spain). Sustainability 12 (17), 1-30.

Shakibaei, S., de Jong, G., Alpkökin, P., \& Rashidi, T. (2021). Impact of the COVID-19 pandemic on travel behavior in Istanbul: A panel data analysis. Sustainable Cities and Society 65.

Shen, J., Duan, H., Zhang, B., Wang, J., Ji, J., Wang, J., . . Shi, X. (2020). Prevention and control of COVID-19 in public transportation: Experience from China. Environmental Pollution 266.

Sun, X., Wandelt, S., \& Zhang, A. (2020). How did COVID-19 impact air transportation? A first peek through the lens of complex networks. Journal of Air Transport Management 89.

Tarasi, D., Daras, T., Tournaki, S., \& Tsoutsos, T. (2021). Transportation in the Mediterranean during the COVID-19 pandemic era. Global Transitions 3, 55-71.

Tian, X., An, C., Chen, Z., \& Tian, Z. (2021). Assessing the impact of COVID-19 pandemic on urban transportation and air quality in Canada. Science of The Total Environment 765, 270.

Tirachini, A., \& Cats, O. (2020). COVID-19 and Public Transportation: Current Assessment, Prospects, and Research Needs. Journal of Public Transportation 22 (1), 1-21.

Zhang, Y., \& Fricker, J. (2021). Quantifying the impact of COVID-19 on non-motorized transportation: A Bayesian structural time series model. Transport Policy 103, 11-20. 
Zhu, Z., Zhong, C., Zhang, K., \& Dong, C. (2020). Epidemic trend of corona virus disease 2019 (COVID-19)in mainland China. Zhonghua yu fang yi xue za zhi[Chinese journal of preventive medicine] 54 (6):E022., 620-624. 